\title{
In memoriam: Academician Andrey L. Mikaelian, SPIE Gold Medal Winner
}

(Published by SPIE on 13 July 2010)

DOI: $10.3103 / \mathrm{S} 1060992 \mathrm{X} 11010085$

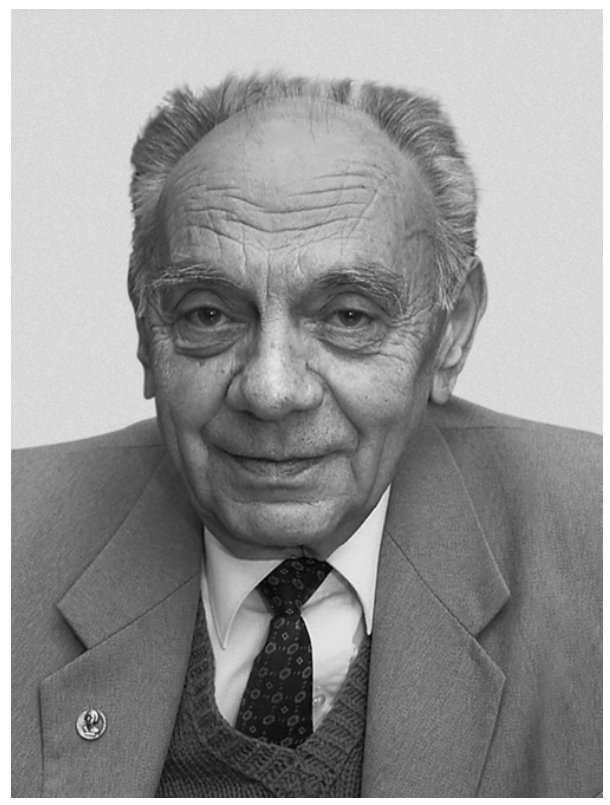

Academician Andrey L. Mikaelian, a recipient of the Gold Medal of SPIE, died on 7 July 2010, at the age of 85.

Mikaelian was a founder of the modern scientific school of radio-optics and made significant contributions to different fields of microwave ferrites, laser techniques, holography, and neural methods of information processing.

Recently he led research in the field of nonlinear optical principles of information processing, creating holographic nanostructures using plasmon resonance for hypersensitive information-processing systems.

During the early 1950s he proposed the idea of magnetooptical effects use for the creation of nonreciprocal waveguide devices, developed the theory of gyrotropic waveguides, and applied these new devices for communication and radio-location systems.

In 1951, long before the era of lasers, he proposed the first optical waveguide "SELFOC" and later developed gradientindex lenses. He pioneered optical waveguides, the wideband properties of which almost two decades later were successfully realized as fiber-optic light conductors and came to be widely employed in optical communication systems.

Mikaelian later developed radio-optical methods of information registration and processing, based on principles of holography. He proposed the method of laser radiation mode selection, created the first single-mode lasers and optoelectronic devices, including the magneto-optical space light modulator (SLM). As a result, the first holographic memory systems were realized.

In 1992 he founded the Institute of Optical Neural Technologies of RAS and was the director of the institute for 10 years. In recent years he served as Scientific Supervisor of IONT RAS.

Among his many national and international awards, Mikaelian received the 1994 SPIE Gold Medal of the Society for his pioneering work.

He was the author of more than 300 papers, numerous Russian patents, and several monographs. He chaired many SPIE-sponsored meetings on optical memory and neural networks and edited several volumes of SPIE Proceedings.

A Fellow of SPIE since 1992, he was the president of SPIE Russia Chapter from 1993 through 1996.

He is survived by his son Michael. 